\title{
Culture Influences How People Divide Continuous Sensory Experience into Events
}

\author{
Khena M. Swallow and Qi Wang ${ }^{\mathrm{b}}$ \\ a. Department of Psychology, Cornell University, Ithaca, NY, USA \\ b. Department of Human Development, Cornell University, Ithaca, NY, USA
}

Khena Swallow

Department of Psychology, Cornell University, 211 Uris Hall, Ithaca, NY 14853

kms424@,cornell.edu

Office: (607) 255-4387

Fax: (607) 255-8433 


\section{Abstract (250 words; 250 word limit)}

Continuous sensory experience is divided into meaningful events as a part of human perception. Current accounts of this process, known as event segmentation, have focused on how it is influenced by characteristics of the experience, such as changes in the situation, or its similarity to prior experiences. However, characteristics of the viewers themselves may shape how an experience is attended and conceptualized. In this study, we test whether one such viewer characteristic, culture, impacts the online segmentation of visual experience. Culture could impact event segmentation (1) by emphasizing different aspects of experiences as being important for comprehension, memory, and communication, and (2) by providing different exemplars of how everyday activities are performed, which objects are likely to be used, and how scenes are laid out. To test both possibilities, Indian and US viewers identified coarse and fine events in videos of everyday activities (e.g., making coffee). Activities were recorded in both Indian and US settings. Consistent with their cultural preference for concrete and analytical processing, US viewers segmented the activities into more events than did Indian viewers. Furthermore, whereas the boundaries identified by US viewers were more strongly associated with concrete visual change, boundaries identified by Indian viewers were more strongly associated with changes in actions and goals. There was no evidence that familiarity with an activity, indicated by the match between a viewer's culture and activity setting, impacted segmentation. Thus, culture impacts event perception by altering the types of information a person prioritizes when dividing experience into meaningful events. 


\section{Significance (120 words; 120 word limit)}

Event segmentation is a fundamental cognitive faculty that plays a critical role in everyday perception, memory, and learning. The finding that culture impacts segmentation challenges the notion that events are optimally defined for a given experience without regard to internal characteristics of an observer. Rather, segmentation may reflect information processing that is optimal for a given person and their goals. This raises the possibility that other group differences, such as those observed in autism spectrum disorders, could also reflect differences in the types of information that are most relevant for the observer. More broadly, these findings highlight that investigations of basic cognitive processes across cultures can reveal underappreciated assumptions about their function while providing deeper insight into their mechanisms. 


\section{Introduction}

Cultural experiences shape how people think, feel, and behave (1-3). Whereas the importance of culture has been generally recognized for human psychological functioning, it is often assumed that culture is irrelevant to basic perceptual and cognitive processes (4). One of these processes is event segmentation, a naturally occurring perceptual process that divides ongoing experience into meaningful, discrete events (5). For example, when watching someone get a cup of coffee, an observer may segment the experience between pouring the coffee and adding cream. By determining when one event ends and another begins, event segmentation thus defines the units of experience over which people learn, remember, and plan for the future (611). Yet, event segmentation may be influenced by cultural factors that guide attentional, perceptual, and conceptual processing (12-15). The current study examines the role of culture in event segmentation, investigating how people from different cultures divide their ongoing, everyday experiences into meaningful events.

Event segmentation occurs as a part of normal perception and reflects changes in ongoing experiences (5). Just like structured activities (16), event segmentation occurs simultaneously at multiple, hierarchically organized grains: small, fine grained events are contained within large, coarse grained events (17). For example, making coffee contains multiple coarse events such as measuring coffee beans, brewing the coffee, and pouring the coffee into a cup. Coarse events also contain fine events: measuring coffee beans might include grabbing the coffee container, opening it, and spooning out the desired amount of beans. The moments that separate events, event boundaries, tend to occur when events change and become less predictable $(18,19)$. People segment continuous experience when there are changes in the visual features of a video (e.g., 19-23), an actor's motion, posture, interactions with objects, and goals, as well as changes 
in the location or time of the event $(19,24-27)$. Correspondingly, when event boundaries are encountered in movies, brain activity is modulated in regions involved in representing spatial and temporal contexts $(28,29)$, understanding others' goals $(25,26)$, and processing visual motion $(23,30)$. Although these features of the situation may be flexibly used to identify event boundaries (22), changes in visual motion, an actor's posture, or his or her action correspond more closely to fine event boundaries, while changes in an actor's goals and the objects he or she is interacting with correspond more closely to coarse event boundaries $(17,19,26,31)$.

Like many basic cognitive and perceptual processes, event segmentation is often assumed to be unaffected by an individual's culture. It has been described as a process that optimizes attention and memory for a particular experience (rather than an individual) by focusing encoding on moments that are important for event comprehension and memory (32). Consistent with this characterization, individuals who process events similarly to their peers and segment at typical (rather than atypical) moments perform better on episodic memory tasks $(8,32-35)$. These and other studies (e.g., 10,11) have utilized the degree with which individuals in Western cultures agree about when event boundaries occur $(19,30)$ to demonstrate the importance of event segmentation for learning and memory.

However, the consistency of a cognitive or perceptual process within one population, in this case, North Americans and Europeans, can mask important properties of these systems that may be revealed only when more diverse populations are examined. For example, in perceptual narrowing, initial sensitivity of newborns to sounds in a variety of languages (phonemes) rapidly shifts to the categorical grouping of sounds that the child's native language does not functionally distinguish (38). Even the way people conceptualize and represent time and space appears to be influenced by culture (39). Thus, culture can impact how people attend to, perceive, and interpret 
the world (1-3). Particularly relevant to the current study, different cultures promote distinctive perceptual styles that reflect differences in the basic allocation of attention during stimulus processing (12), perhaps arising from different socio-ecological contexts associated with traditional subsistence methods (e.g., rice farming versus wheat farming) $(40,41)$. Whereas Asians often attend to relationships among individuals, objects, and events, processing them more holistically, Westerners often focus on the individual objects and events themselves, processing them more analytically $(13,42,43)$. As a result, Westerners may perceive more discrete events in an observed activity than Asians who are more likely to perceive things as interrelated as a whole $(14,44)$. People in Eastern cultures also may attend more to the actions, goals, and perspectives of others $(15,40,45)$. They therefore may rely more on changes in an actor's goals and intentions, rather than on concrete visual change, when dividing observed activities into meaningful events.

In addition to influencing the "perceiver," culture influences what is "perceived" (46). Mundane activities such as making coffee or doing laundry can differ considerably across cultural communities in the manner and matter of achieving the intended goals. For example, automatic drip coffee machines are often used in the West, while other parts of the world may use a percolation method. As a result, while people are familiar with the activities from their own culture, activities from other cultures are sometimes unfamiliar. Event segmentation may reflect the learned statistical structure of activities, such that sets of actions that frequently co-occur or occur in a given sequence are grouped into larger, more coarse grained events, resulting in more "chunking" $(7,47-50)$. If this is the case, then people should identify more, finer grained events in unfamiliar activities from other cultures than in familiar activities from their own culture. 
To examine the role of culture in the way people divide ongoing experience into meaningful events, 74 participants in India and 78 participants in the US marked event boundaries in videos of everyday activities (see Methods and Supplementary Information for additional information). For the segmentation task, participants watched a video and pressed a button whenever they believed one natural and meaningful unit of activity ended and another began (51). Each participant segmented an Indian version and a US version (setting) of two activities that were selected from a set of four (doing laundry, making a bed, washing dishes, and making coffee). Using standard segmentation procedures, participants segmented each video twice, once to identify coarse events, and once to identify fine events (Figure 1). This design is necessary for examining how fine events are organized within coarse events, and increases statistical power by manipulating segmentation grain within subjects. Afterwards, participants indicated their familiarity with the activities and the similarity of the activity to their own way of performing the action. They then completed questionnaires to measure demographics and analysis/holism characteristics. Activities recorded in the setting that matched the viewers' culture were rated more highly in familiarity and similarity those that did not match (Supplementary Information). In addition, Indian viewers scored higher on interdependence and holism than US viewers (scores were similar for independence; Supplementary Information).

This procedure allowed us to test several specific predictions about cultural influences on event segmentation. One possibility is that culture influences segmentation by influencing which aspects of events are prioritized during experience (attentional focus hypothesis). US and Indian cultures differ in their tendency to perceive situations more analytically, breaking it into parts, or more holistically, emphasizing the interrelatedness between parts $(14,44)$. If these differences impact segmentation, then US viewers should identify events at a finer grain (break the events 
into more parts) than Indian viewers. For similar reasons, US viewers should identify event boundaries that are more strongly associated with concrete features of the activity (e.g., visual changes in the video, such as those produced by actor motion) than Indian viewers, whose event boundaries should be more strongly associated with underlying features of the activity (e.g., goal changes). These differences in attention to goal changes and visual change might also lead viewers from India and the US to identify boundaries at different times. Culture may also impact segmentation by altering learned expectations about how specific types of events unfold (familiarity hypothesis). When viewers segment activities from their own culture rather than another culture, their knowledge of the activity may allow them to segment at a coarser grain, to better organize fine events within coarse events, and to increase agreement about when event boundaries occur. To test these predictions, we asked whether culture affected how often participants segmented, when they segmented, and which features they used to segment the activities.

\section{Results}

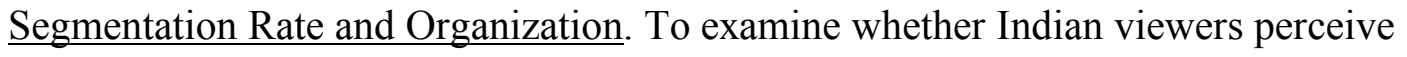
coarser events than US viewers, we measured whether viewer culture affected the rate at which the events were segmented. This should produce a main effect of viewer culture. In addition, individuals who are more familiar with an activity may group more of the action together, segmenting it at a lower rate than those who are not familiar with the activity $(17,31,48)$. This should produce an interaction between viewer culture and activity setting, with segmentation rates being lower when viewer culture and activity setting match than when they do not. Because 
the activities were relatively brief the effects of viewer culture and familiarity on segmentation rate may only be reflected in fine segmentation (similar to 44).

Button presses per minute were analyzed in a mixed effects ANOVA with activity setting (Indian/US setting), viewer culture (Indian/US viewer), grain level (coarse/fine), and all interactions as factors. All main effects and interactions were significant, including the grain $\mathrm{x}$ culture x setting interaction, $F(1,150)=8.894, p=.003, \eta_{p}{ }^{2}=.056$ (statistics for all analyses are reported in full in the Supplementary Information). As illustrated in Figure 2A, US viewers identified more fine boundaries than did Indian viewers, supporting the attentional focus hypothesis. The difference in the number of fine boundaries identified by US and Indian viewers was present for activities in both settings. Contradicting the familiarity hypothesis, however, neither US nor Indian viewers segmented activities from their own culture at lower rates than activities from the other culture. In fact, the tendency for US viewers to segment at a higher rate than Indian viewers was greater, not reduced, for activities set in the US, $t(117.53)=2.84, p=$ .005 , which should have been chunked more by US viewers and less by Indian viewers.

The effect of culture on segmentation rate could reflect differences in the tendency to break coarse units into fine units or less attention to the hierarchical structure of the activity. However, additional analyses showed that both groups tended to hierarchically organize fine events within coarse events, regardless of setting (Supplementary Information). Taken together, while both US and Indian viewers segment events hierarchically, US viewers break events into smaller parts than do Indian viewers, supporting the attentional focus hypothesis. Furthermore, in contrast to the prediction that greater familiarity with an activity should increase chunking, segmentation rate and hierarchical organization were not reliably influenced by the match between the viewer's culture and activity setting. 
Boundary Agreement. In addition to differing in the level of granularity at which they identify fine grained events, US and Indian viewers may identify event boundaries at different times in the activities. This could occur both as a result of differences in attention to concrete visual aspects of the activity vs. actor goals (attentional focus hypothesis) and as a consequence of differences in familiarity with the activity (familiarity hypothesis). Figure 1 illustrates a group time series created by calculating the proportion of US and Indian viewers who identified a coarse or fine event boundary for each second of one of the activities (see Supplementary Information for all group time series). The pattern of data suggests that, although the peaks and valleys of the time series produced by Indian and US viewers largely overlap, there are points at which they appear to differ.

To quantitatively evaluate whether differences in the time series reflect the effects of culture and setting on boundary placement, the degree to which individuals placed event boundaries at similar times as other viewers was examined by calculating an agreement index (34). For each participant, separate coarse and fine individual time series were generated by coding whether a boundary was identified during each second of each activity they viewed. The correlation between an individual time series and the average time series of the remaining US or Indian viewers (group time series) was then calculated and scaled by the minimum and maximum correlations that were possible, given the number of times that participant pressed the button (34).

If culture influences when people identify boundaries, then an individual should have a higher agreement index for the group from the same culture than for the group from the other, different culture. Because the effects of viewer culture and comparison group (same/different culture) on agreement differed across grains (Figures 2B, 2C), we focused on each grain 
separately, grain $\mathrm{x}$ viewer culture $\mathrm{x}$ comparison group interaction, $F(1,150)=25.917, p<.001$, $\eta_{p}{ }^{2}=.147$. For coarse boundaries, agreement was greater for the same group than for the different group for both Indian and US viewers, main effect of comparison group $F(1,150)=$ $4.742, p=.031, \eta_{p}{ }^{2}=.03$. Although the effects were small, they suggest that Indian and US viewers sometimes identified coarse grained event boundaries at different times, potentially reflecting differences in attentional focus when identifying coarse events.

A different pattern was observed for fine boundaries, however. For both Indian and US viewers, agreement was highest for US group boundaries (different group for Indian viewers and same group for US viewers), comparison group $\mathrm{x}$ viewer culture interaction $F(1,150)=88.506, p$ $<.0001, \eta_{p}{ }^{2}=.371$. These effects were present even when the number of boundaries identified by each group was equated (Supplemental Information), ruling out differences in segmentation rate as a potential explanation for higher agreement with the US group time series. Rather, these results suggest that, on average, the fine boundaries identified by US viewers tended to be ones that both Indian and US viewers were likely to identify.

Individuals who are familiar with an activity may agree on boundary placement more than individuals who are unfamiliar with an activity. For both coarse and fine segmentation, agreement was greater for activities set in the US than for activities set in India, main effect of activity setting, $F(1,150)=11.378, p=.001, \eta_{p}^{2}=.071$, for coarse, $F(1,150)=12.275, p=.001$, $\eta_{p}^{2}=.076$, for fine. Because this pattern was present for viewers from both cultures, nonsignificant setting $\mathrm{x}$ culture interaction, $F(1,150)=1.554, p=.214$, for coarse, $F(1,150)=$ $0.566, p=.453$, for fine, there was no evidence that boundary agreement depended on the match between viewer culture and activity setting. This is inconsistent with familiarity influencing individual-group agreement. 
Features Related to Segmentation. The findings that Indian and US viewers identified fine boundaries at different rates and placed coarse boundaries at slightly different times are consistent with the attentional focus hypothesis. However, this hypothesis also suggests that Indian and US viewers use different types of information to segment events. Whereas Indian viewers should focus more on changes in an actor's goals, US viewers should focus more on concrete features like visual change.

To examine whether culture impacts the types of information viewers use to segment events, action and goal changes were coded for each second of each video. For visual change, the amount of frame to frame change in the videos was quantified using the visual activity index (VAI) (52). VAI and change type (none/action/goal) were used as predictors in a generalized linear mixed effects model of the segmentation data (see Methods for detailed description).

For both coarse and fine grained segmentation, viewer culture influenced the relationship between segmentation and video features. Increases in the VAI increased the likelihood that a coarse boundary would be identified, $F=330.442, p<.0001$, but the effect was stronger for US viewers than for Indian viewers (odds ratio for Indian viewers = 1.291, US viewers = 1.465; see also Supplementary Information), VAI x culture interaction, $F=13.020, p=.0003$ (Figure 3a). Change type also influenced the likelihood that a coarse boundary would be identified, main effect of change type, $F=99.303, p<.0001$ (Figure $3 b$ ). In contrast to the VAI, however, the effects of action and goal changes on coarse segmentation were stronger for Indian viewers than for US viewers (action change odds ratio for Indian viewers $=1.056$, US viewers $=0.936$, goal change odds ratio Indian viewers $=1.824$, for US viewers $=1.443$ ), change type $\mathrm{x}$ culture interaction, $F=5.864, p=.003$. A similar pattern was observed for fine segmentation, which increased with the VAI (odds ratio for Indian viewers $=1.183$, for US viewers $=1.206$ ), $F=$ 
$225.889, p<.001$, and varied across change type, $F=575.237, p<.001$ (Figure $3 c$ ). However, only change type interacted with viewer culture, $F=26.498, p<.001$ (Figure 3d). Fine boundaries identified by Indian viewers were more strongly associated with goal changes than were those identified by US viewers (odds ratio for Indian viewers $=2.149$, for US viewers $=$ 1.649). To summarize, both Indian and US viewers were more likely to identify coarse and fine event boundaries when there was more visual change and when there was a goal change. However, relative to US viewers, Indian viewers' segmentation was more strongly associated with action or goal changes. ${ }^{1}$ In contrast, US viewers' coarse segmentation was more strongly associated with increases in visual change than was Indian viewers' segmentation.

The relationships between event segmentation and change type also differed across activity settings, $F=3.054, p=.047$ for coarse, $F=58.393, p<.0001$ for fine. Coarse boundaries were more strongly associated with action changes in Indian settings than in US settings (odds ratio for Indian settings $=1.063$, for US settings $=0.930$; see also Supplementary Information). Fine boundaries also were more strongly associated with action changes and goal changes in Indian settings than in US settings (action change odds ratio for Indian settings $=$ 1.248 , for US settings $=1.121$; goal change odds ratio for Indian settings $=2.301$, for US settings $=1.540)$. This suggests that viewers relied more on action and goal changes for the activities set in India than those set in the US. However, because activity setting never interacted with viewer culture, these results could reflect differences in the setting itself, how the actors structured their activities, or other idiosyncratic differences, rather than familiarity.

\section{Discussion}


Event segmentation plays a central role in numerous cognitive processes, influencing early learning of intentionality and language (53), the allocation of attention over time (48), and the division of rich perceptual experiences into episodes that form the basis of short-term, episodic, and autobiographical memory $(8,10,11,29,44,54)$. The current study revealed two previously unknown aspects of event segmentation: First, that culture impacts the degree to which individuals divide their experience into meaningful units as it occurs. Second, that culture impacts the types of information people use to determine when those units end and begin. These findings provide critical evidence that event segmentation, although a basic perceptual process, is subject to cultural influences.

The effects of culture on segmentation were reflected in the way viewers defined events but not via familiarity with the activities themselves. The locus of the effect of culture on segmentation was in the "perceiver," rather than the "perceived." In line with previous findings that interdependent cultures may engage in more relational processing and focus more on the actions, goals and perspectives of others $(12-15,40,44,45)$, Indian viewers segmented the activities into larger chunks than did US viewers. Indians viewers also identified event boundaries that were more strongly related to actor actions and goals than US viewers. In contrast, US viewers identified coarse event boundaries that were more strongly related to changes in concrete visual features of the activity. These cultural differences were evident in both activity settings, suggesting that the "cultural lens" through which people perceive and process information manifests across both familiar and unfamiliar contexts.

These findings suggest a potential role of social and ecological contexts in shaping event segmentation during development. Culture captures patterns of thinking about and construing the world that are shared by social groups $(1,2,14)$. It is possible that the way caregivers talk about 
events and provide feedback to young children about how to describe their own experiences subtly shapes how children come to define when events end and begin (e.g., 55, 56). Yet the role of social and ecological contexts in shaping how events are segmented has not been studied, despite growing evidence that such social interactions impact other types of perceptual learning in infancy (57) and childhood (58). These findings highlight the need for additional work examining how events may be defined by the cultural (social and ecological) context in which individuals develop.

The current findings also suggest that culture may influence segmentation by altering which aspects of an experience (e.g., goals vs. visual changes) are attended. Accounts of event segmentation generally focus on how segmentation itself (e.g., 5, 29) or learning about which actions tend to co-occur $(7,47,50)$, guide attention to events over time, but overlook the role of attentional mechanisms and biases in guiding when people segment events. The impact of viewer characteristics on segmentation emphasizes the importance of understanding the dynamic interplay between variations in when and what people attend to and how they divide their experience into meaningful events. Better characterizing this relationship may be particularly important for understanding how neuropsychological disorders, such as mild cognitive impairment, Alzheimer's Disease, autism, and attention deficit hyperactivity disorder, influence event segmentation and memory $(32,33,59,60)$. The implication that segmentation may not be uniform across neurotypical individuals raises the possibility that some differences in segmentation across both typical and neurotypical groups could reflect differences in the types of information that attract attention, differences in affective states, and even trait and state differences in arousal (e.g, 61, 62). 
Interestingly, there was no effect of familiarity on segmentation. Cognitive and developmental work emphasizes the importance of learned event schemata and statistical structure in event perception, comprehension, and memory $(5,7,47,63,64)$. However, prior knowledge of the activity and its context does not always have a significant effect on segmentation $(27,31)$, raising questions about the conditions under which different types of knowledge contribute to event segmentation. We suggest that viewers may flexibly rely on different sources of information to determine when one event ends and another begins. In the case of the unfamiliar activities, participants could use general knowledge about human behavior that constrains what happens and when. For example, the fact that multiple actions were performed on the same object (or in a similar location), in quick succession, may be sufficient to at least partially hierarchically organize a completely novel sequence of actions into meaningful events. Which features are used for segmentation therefore may depend on which sources of information are available (22), salient (65), and important for the viewer's comprehension and later memory $(14,44,54)$.

In conclusion, although there have been strong calls for researchers to attend to the role of culture in shaping human perception and cognition (1-3), culture is still often overlooked in theorization and empirical research in psychology $(4,66)$. Studying only participants from Western, Educated, Industrialized, Rich, Democratic societies (WEIRD; 67) risks an incomplete or even misleading understanding of how basic cognitive and perceptual processes work. The present findings demonstrate that event segmentation, as a basic cognitive faculty important for human learning, memory, and survival, is indeed shaped by culture. They further illustrate that differences in how healthy people perceive and conceptualize events need to be incorporated into current theories of event segmentation. 


\section{Materials and Methods}

Participants. All participants provided informed consent, the procedures were approved by Cornell's Institutional Review Board, and all data were collected in accordance with the Declaration of Helsinki. A power analysis (G*Power; 68) indicated that a sample size of 138 is required to achieve a power $(1-\beta)$ of .9 to detect an interaction of within- and between-subjects factors (two levels each) with an effect of size of $\eta_{p}{ }^{2}=.019(f=0.14)$ and $\alpha=.05$. To ensure that an effect of this size could be detected with reasonable power, 152 volunteers (19-58 years old; 47 females, 105 males) satisfactorily completed the experiment after being recruited through Amazon's Mechanical Turk using TurkPrime. They were compensated $\$ 5.00$ or $\$ 7.50$ for their time.

Stimuli. Eight videos depicting four different activities in two different settings were recorded. Each activity was recorded in an Indian setting (Bangaluru, Karnataka, India) and in a US setting (Ithaca, New York, United States). The videos differed in their location, the actor performing the activity, how the actor performed the activity, and the presence of different cultural artifacts (e.g., decorations, utensils, clothing, etc.). As a result, there were significant stimulus differences across settings (see Figure 1 and Figure S1). However, an effort was made to use actors of similar ages and genders across the two settings (not necessarily matched to activity).

Design and Procedure. Participants performed the segmentation task followed by online questionnaires, including familiarity and similarity ratings for the activities, the self-construal scale (69), and the analysis-holism scale (70). For the segmentation task, each participant viewed four videos (two activities repeated in each setting), two times each. Participants pressed a button 
on their keyboard every time they believed one natural and meaningful unit of activity ended and another began (51). Participants segmented each video twice, once to identify the largest (coarse) units and once to identify the smallest (fine) units. Practice for each segmentation grain included a shaping procedure to ensure participants were segmenting within a pre-specified range (see Supplementary Information).

Analyses. To examine the relationship between features of the video and boundary identification, generalized linear mixed effects models were fit to the segmentation data using glmer in R (lmer4) (71) and evaluated with emmeans (72). Coarse and fine segmentation data were analyzed separately to reduce model complexity. Models included the presence or absence of a boundary for each second of the videos as the dependent variable, and the VAI and change type (none/action/goal) as fixed effects. Viewer culture, activity setting, and their interactions with each other, the VAI, and activity setting were also included as fixed effects. Random intercepts for subject and video were included in the models. More complex models with more interaction terms or random slopes failed to converge. Deidentified and aggregated data are available at https://osf.io/y9gsq/?view only=fba7a03b6d4a4f039b90479944f2f45b.

\section{Footnotes}

1. Action and goal changes were identified by US researchers. If culture influences how a viewer identifies these, then our results may underestimate the relationship between action and goal changes and Indian viewers' segmentation and the effect of culture on segmentation. 
Acknowledgments. This work was funded by the Institute for Social Sciences at Cornell

University. The authors would like to thank James Cutting and Michael Goldstein for comments on earlier drafts of this manuscript, John MacDonald for programming assistance, Erika Mudrack with Cornell Statistical Consulting for advice on the statistical analyses, and Taylor Beauvais, Clara Lee, Isabella Poulos, and Hyung Sop Shin for their help with conducting the study. We are grateful to the eight actors who helped make the videos.

\section{References}

1. Markus HR, Kitayama S (1991) Culture and the self: Implications for cognition, emotion, and motivation. Psychological Review 98(2):224-253.

2. Hong Y, Morris MW, Chiu C, Benet-Martínez V (2000) Multicultural minds: A dynamic constructivist approach to culture and cognition. American Psychologist 55(7):709-720.

3. Kitayama S, Cohen D (2010) Handbook of Cultural Psychology (Guilford Press).

4. Wang Q (2016) Why Should We All Be Cultural Psychologists? Lessons From the Study of Social Cognition. Perspect Psychol Sci 11(5):583-596.

5. Zacks JM, Speer NK, Swallow KM, Braver TS, Reynolds JR (2007) Event perception: A mind/brain perspective. Psychological Bulletin 133(2):273-293.

6. Bailey HR, Kurby CA, Giovannetti T, Zacks JM (2013) Action perception predicts action performance. Neuropsychologia 51(11):2294-2304.

7. Baldwin DA, Andersson A, Saffran JR, Meyer M (2008) Segmenting dynamic human action via statistical structure. Cognition 106:1382-1407. 
8. Chen J, et al. (2017) Shared memories reveal shared structure in neural activity across individuals. Nat Neurosci 20(1):115-125.

9. Ezzyat Y, Davachi L (2010) What Constitutes an Episode in Episodic Memory? Psychological Science. doi:10.1177/0956797610393742.

10. Swallow KM, et al. (2011) Changes in Events Alter How People Remember Recent Information. Journal of Cognitive Neuroscience 23(5):1052-1064.

11. Swallow KM, Zacks JM, Abrams RA (2009) Event boundaries in perception affect memory encoding and updating. Journal of Experimental Psychology: General 138(2):236-257.

12. Kitayama S, Murata A (2013) Culture Modulates Perceptual Attention: An Event-Related Potential Study. Social Cognition 31(6):758-769.

13. Nisbett RE, Miyamoto Y (2005) The influence of culture: holistic versus analytic perception. Trends in Cognitive Sciences 9(10):467-473.

14. Wang Q (2013) The Autobiographical Self in Time and Culture (Oxford University Press).

15. Wang Q (2006) Earliest Recollections of Self and Others in European American and Taiwanese Young Adults. Psychological Science 17(8):708-714.

16. Vallacher RR, Wegner DM (1987) What do people think they're doing? Action identification and human behavior. Psychological Review 94(1):3-15.

17. Zacks JM, Tversky B, Iyer G (2001) Perceiving, remembering, and communicating structure in events. Journal of Experimental Psychology: General 130(1):29-58. 
18. Zacks JM, Kurby CA, Eisenberg ML, Haroutunian N (2011) Prediction Error Associated with the Perceptual Segmentation of Naturalistic Events. Journal of Cognitive Neuroscience 23(12):4057-4066.

19. Newtson D, Engquist G, Bois J (1977) The objective basis of behavior units. Journal of Personality and Social Psychology 35(12):847-862.

20. Cutting JE, Brunick KL, Candan A (2012) Perceiving event dynamics and parsing Hollywood films. Journal of Experimental Psychology: Human Perception and Performance 38(6):1476-1490.

21. Hard BM, Recchia G, Tversky B (2011) The shape of action. Journal of Experimental Psychology: General 140(4):586-604.

22. Swallow KM, Kemp JT, Candan Simsek A (2018) The role of perspective in event segmentation. Cognition 177:249-262.

23. Zacks JM, Swallow KM, Vettel JM, McAvoy MP (2006) Visual motion and the neural correlates of event perception. Brain Research 1076:150-162.

24. Magliano JP, Miller J, Zwaan RA (2001) Indexing space and time in film understanding. Applied Cognitive Psychology 15:533-545.

25. Zacks JM, Speer NK, Swallow KM, Maley CJ (2010) The Brain's Cutting-Room Floor: Segmentation of Narrative Cinema. Front Hum Neurosci 4. doi:10.3389/fnhum.2010.00168. 
26. Zacks JM, Speer NK, Reynolds JR (2009) Segmentation in reading and film comprehension. Journal of Experimental Psychology: General 138(2):307-327.

27. Zacks JM, Kumar S, Abrams RA, Mehta R (2009) Using movement and intentions to understand human activity. Cognition 112(2):201-216.

28. Brunec IK, Moscovitch M, Barense MD (2018) Boundaries Shape Cognitive Representations of Spaces and Events. Trends in Cognitive Sciences 22(7):637-650.

29. Baldassano C, et al. (2017) Discovering Event Structure in Continuous Narrative Perception and Memory. Neuron 95(3):709-721.e5.

30. Speer NK, Swallow KM, Zacks JM (2003) Activation of human motion processing areas during event perception. Cognitive, Affective, and Behavioral Neuroscience 3(4):335-345.

31. Hard BM, Tversky B, Lang DS (2006) Making sense of abstract events: Building event schemas. Memory \& Cognition 34(6):1221-1235.

32. Sargent JQ, et al. (2013) Event segmentation ability uniquely predicts event memory. Cognition 129(2):241-255.

33. Zacks JM, Speer NK, Vettel JM, Jacoby LL (2006) Event understanding and memory in healthy aging and dementia of the Alzheimer Type. Psychology and Aging 21(3):466-482.

34. Kurby CA, Zacks JM (2011) Age differences in the perception of hierarchical structure in events. Mem Cogn 39(1):75-91.

35. Bailey HR, et al. (2013) Medial Temporal Lobe Volume Predicts Elders’ Everyday Memory. Psychol Sci 24(7):1113-1122. 
36. Gold DA, Zacks JM, Flores S (2017) Effects of cues to event segmentation on subsequent memory. Cogn Research 2(1):1.

37. Boltz M (1992) Temporal accent structure and the remembering of filmed narratives. Journal of Experimental Psychology: Human Perception \& Performance 18(1):90-105.

38. Kuhl PK (2010) Brain Mechanisms in Early Language Acquisition. Neuron 67(5):713-727.

39. Boroditsky L, Gaby A (2010) Remembrances of Times East: Absolute Spatial Representations of Time in an Australian Aboriginal Community. Psychological Science 21(11):1635-1639.

40. Uskul AK, Kitayama S, Nisbett RE (2008) Ecocultural basis of cognition: Farmers and fishermen are more holistic than herders. PNAS 105(25):8552-8556.

41. Talhelm T, et al. (2014) Large-Scale Psychological Differences Within China Explained by Rice Versus Wheat Agriculture. Science 344(6184):603-608.

42. Nisbett RE, Masuda T (2003) Culture and point of view. PNAS 100(19):11163-11170.

43. Nisbett RE, Peng K, Choi I, Norenzayan A (2001) Culture and systems of thought: Holistic versus analytic cognition. Psychological Review 108(2):291-310.

44. Wang Q (2009) Are Asians forgetful? Perception, retention, and recall in episodic remembering. Cognition 111(1):123-131.

45. Wu S, Keysar B (2007) The Effect of Culture on Perspective Taking. Psychol Sci 18(7):600-606. 
46. Quinn N (2011) Event Sequencing as an Organizing Cultural Principle. Ethos 39(3):249278.

47. Buchsbaum D, Griffiths TL, Plunkett D, Gopnik A, Baldwin D (2015) Inferring action structure and causal relationships in continuous sequences of human action. Cognitive Psychology 76:30-77.

48. Kosie JE, Baldwin D (2019) Attention rapidly reorganizes to naturally occurring structure in a novel activity sequence. Cognition 182:31-44.

49. Schapiro AC, Rogers TT, Cordova NI, Turk-Browne NB, Botvinick MM (2013) Neural representations of events arise from temporal community structure. Nat Neurosci advance online publication. doi:10.1038/nn.3331.

50. Swallow KM, Zacks JM (2008) Sequences learned without awareness can orient attention during the perception of human activity. Psychonomic Bulletin \& Review 15(1):116-122.

51. Newtson D (1973) Attribution and the unit of perception of ongoing behavior. Journal of Personality and Social Psychology 28(1):28-38.

52. Cutting JE, DeLong JE, Brunick KL (2011) Visual activity in Hollywood film: 1935 to 2005 and beyond. Psychology of Aesthetics, Creativity, and the Arts 5(2):115-125.

53. Friend M, Pace A (2011) Beyond event segmentation: Spatial- and social-cognitive processes in verb-to-action mapping. Developmental Psychology 47(3):867-876.

54. Wang Q (2009) Once upon a Time: Explaining Cultural Differences in Episodic Specificity. Social and Personality Psychology Compass 3(4):413-432. 
55. Reese E, Newcombe R (2007) Training Mothers in Elaborative Reminiscing Enhances Children?s Autobiographical Memory and Narrative. Child Development 78(4):1153-1170.

56. Wang Q (2007) “Remember When You Got The Big, Big Bulldozer?” Mother-Child Reminiscing Over Time and Across Cultures. Social Cognition 25(4):455-471.

57. Altvater-Mackensen N, Grossmann T (2015) Learning to Match Auditory and Visual Speech Cues: Social Influences on Acquisition of Phonological Categories. Child Development 86(2):362-378.

58. Senzaki S, Masuda T, Takada A, Okada H (2016) The Communication of Culturally Dominant Modes of Attention from Parents to Children: A Comparison of Canadian and Japanese Parent-Child Conversations during a Joint Scene Description Task. PLOS ONE 11(1):e0147199.

59. Zalla T, Labruyère N, Georgieff N (2013) Perceiving Goals and Actions in Individuals with Autism Spectrum Disorders. J Autism Dev Disord 43(10):2353-2365.

60. Ryan J, Rogers M (2018) Event Segmentation Deficits in ADHD. J Atten Disord:1087054718799929.

61. Gable PA, Harmon-Jones E (2008) Approach-Motivated Positive Affect Reduces Breadth of Attention. Psychol Sci 19(5):476-482.

62. Fair DA, Bathula D, Nikolas MA, Nigg JT (2012) Distinct neuropsychological subgroups in typically developing youth inform heterogeneity in children with ADHD. PNAS 109(17):6769-6774. 
63. Bower GH, Black JB, Turner TJ (1979) Scripts in memory for text. Cognitive Psychology 11(2):177-220.

64. Schank RC, Abelson RP (1977) Scripts, plans, goals and understanding: An inquiry into human knowledge structures (Lawrence Erlbaum, Oxford, England).

65. Bailey HR, Kurby CA, Sargent JQ, Zacks JM (2017) Attentional focus affects how events are segmented and updated in narrative reading. Memory \& Cognition 45(6):940-955.

66. Rad MS, Martingano AJ, Ginges J (2018) Toward a psychology of Homo sapiens : Making psychological science more representative of the human population. Proceedings of the National Academy of Sciences 115(45):11401-11405.

67. Henrich J, Heine SJ, Norenzayan A (2010) The weirdest people in the world? Behavioral and Brain Sciences 33(2-3):61-83.

68. Faul F, Erdfelder E, Lang A-G, Buchner A (2007) G*Power 3: a flexible statistical power analysis program for the social, behavioral, and biomedical sciences. Behav Res Methods 39(2):175-191.

69. Singelis TM (1994) The Measurement of Independent and Interdependent Self-Construals. Pers Soc Psychol Bull 20(5):580-591.

70. Choi I, Koo M, Jong An Choi (2007) Individual Differences in Analytic Versus Holistic Thinking. Pers Soc Psychol Bull 33(5):691-705.

71. Bates D, et al. (2018) lme4: Linear Mixed-Effects Models using "Eigen” and S4 Available at: https://CRAN.R-project.org/package=lme4 [Accessed August 14, 2018]. 
72. Lenth R, Singmann H, Love J, Buerkner P, Herve M (2018) emmeans: Estimated Marginal Means, aka Least-Squares Means Available at: https://CRAN.Rproject.org/package=emmeans [Accessed January 7, 2019]. 


\section{Figures}
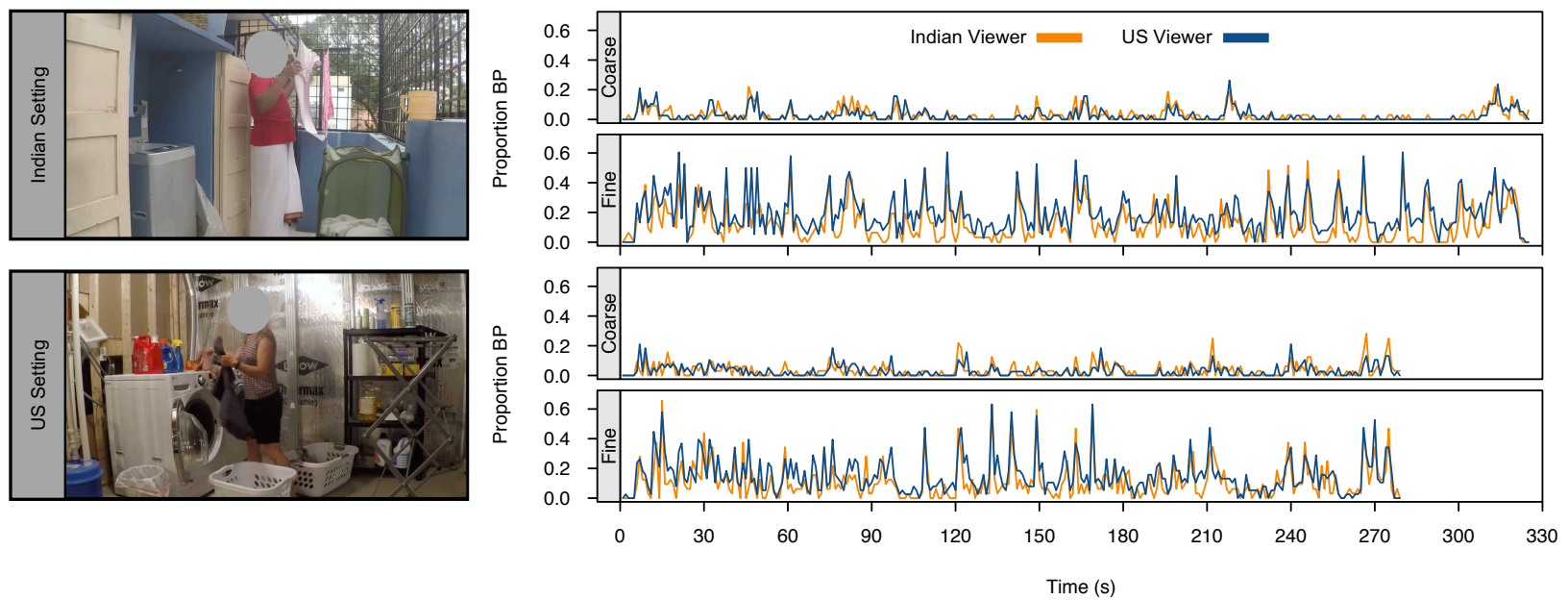

Fig. 1. The proportion of Indian (orange line) and US (blue line) viewers that pressed a button (BP) for each second of the laundry activity in the Indian Setting (two upper right panels) and in the US Setting (two lower right panels) while performing the coarse and fine segmentation tasks.
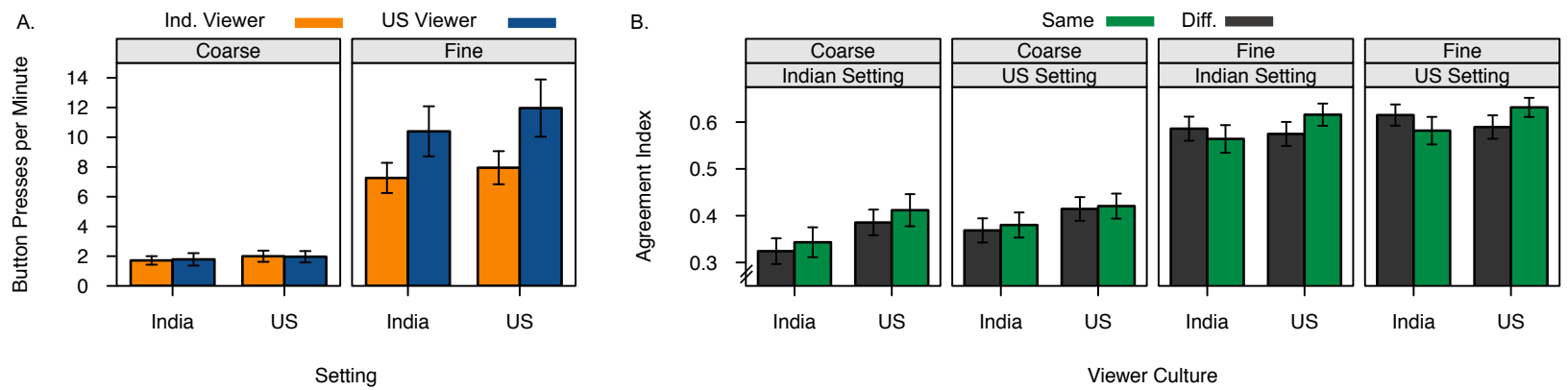

Fig. 2. The effects of culture on the number and timing of event boundaries that viewers identified. (A) Segmentation rates across grains, activity setting, and viewer culture. (B) Individual-group agreement in coarse and fine boundary placement. Error bars indicate $95 \%$ confidence intervals. 

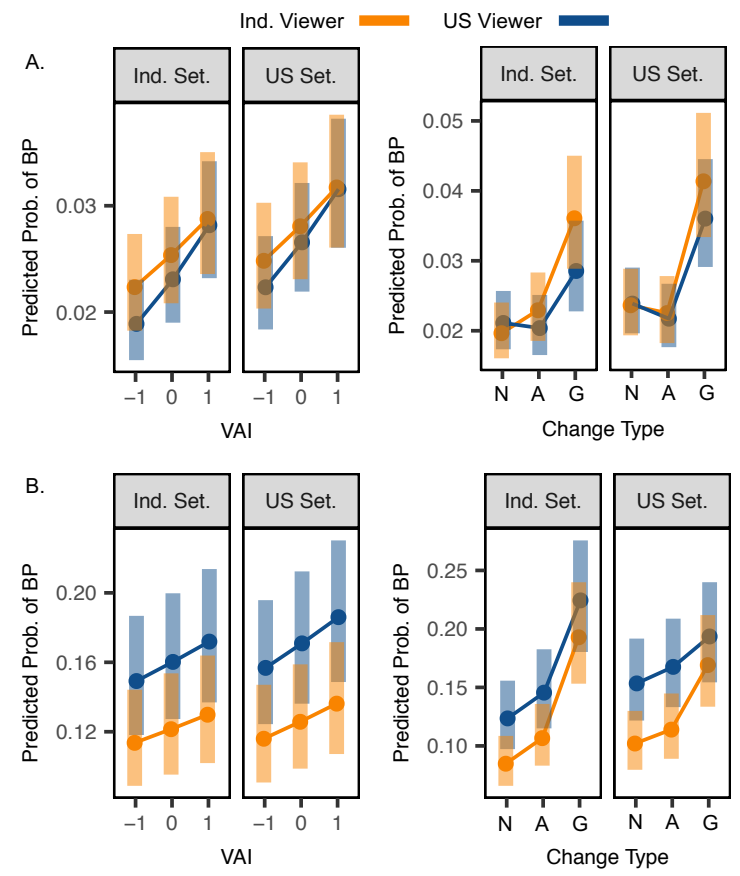

Fig. 3. The relationship between boundary identification and video features. (A) Model based predictions of coarse boundary identification across viewer culture, activity setting, and the VAI (left) or Change Type (right). (B) Model based predictions of fine boundary identification across viewer culture, activity setting, and the VAI (left) or Change Type (right). For VAI, $0=$ mean and $+/-1=1$ standard deviation. For Change Type, $\mathrm{N}=$ none, $\mathrm{A}=$ action, $\mathrm{G}=$ goal. Error bars represent $95 \%$ confidence intervals. 


\section{Supplementary Information Text}

\section{Methods}

Participant Screening. Data from unreliable participants were avoided or removed prior to analyses using several approaches. First, after performing the segmentation task participants were required to copy a random string, click a link to a survey, and then paste the string in an appropriate box. Twelve participants that completed the segmentation task did not complete this step. Second, before they could start the segmentation task participants needed to perform the practice segmentation task within predefined parameters (see Design and Procedure). Similar to shaping procedures used in the lab, participants repeated the practice segmentation task until the number of times they pressed the button was within an acceptable range (based on task performance of participants in the lab). If participants did not perform the task within this range, they were told to identify larger/smaller events and repeated the practice. The practice was performed for both coarse and fine segmentation (once at the beginning and once mid-way through the experiment), and participants had to successfully complete both practices to finish the task. 105 participants performed the first practice task at least once, but did not complete the experiment. Of these, 18 participants also performed the second practice at least once, but did not complete the experiment. In addition to screening out unreliable participants, this procedure ensured that participants could incorporate performance feedback and follow instructions. Finally, participants were excluded if, after passing the practice tasks, they did not follow the instructions when segmenting the videos (they identified more coarse boundaries than fine boundaries, or failed to identify any coarse boundaries). Fifteen participants (12 Indian and 3 US) that completed the experiment were excluded from the final sample for this reason.

Stimuli. Videos were recorded using a GoPro Hero 4 Silver edition (1920x1080 pixels, 29.98 fps, narrow field of view, durations in Table S1) mounted on a stationary tripod or stable surface. The tripod was located several feet away from the actor, such that the camera's field of view included the entire space in which the actor performed the activity. The activity was typically captured from the side, though the actor sometimes faced the camera or turned his or her back to it. There were no camera movements. The audio track was removed and the videos were trimmed so the actor walked into the frame 5 seconds after the video began and walked out 5 seconds before the video ended. Videos were resized to $800 \times 456$ pixels and optimized for the web using Handbrake (1). Otherwise, the videos were unaltered.

Feature Coding. The videos were coded for several features that have previously been shown to influence segmentation: visual change, action changes, and goal changes. Briefly, visual change was quantified using the visual activity index (VAI), which uses the correlation between the grayscale values of two consecutive frames to estimate the amount of visual change in the stimulus from one moment to the next. In the current study every $5^{\text {th }}$ frame was compared to the frame four places behind it (e.g., frame 5 was compared to frame 1). The larger the VAI, the more the video changed. Action changes and goal changes in each video were coded by two raters. Actions were defined as the smallest intentional movements that change the state of the actor, an object, the environment, or the actor's relationship to objects or the environment. Pauses in movement longer than 0.5 seconds that indicated looking or thinking were also coded. Repetitive motions that happened over a brief period of time were grouped (e.g., each turn of a lid to open a container). Action changes were the times that separated two different actions. Goals were defined as internal states that organized actions into purposeful sequences of 
behavior, where actions are performed "in order to" achieve this immediate goal. As a result, actions were grouped within goals (see, for example, 2) and goal changes were the subset of action changes that marked when an action was performed for a new goal. Raters showed adequate levels of agreement, with Cohen's Kappa $=.829$. Discrepancies were resolved through discussion.

Design and Procedure. After providing informed consent, participants performed the segmentation task followed by online questionnaires.

Segmentation Task. Participants viewed four videos (two activities repeated in each setting), two times each to perform the segmentation task (3). For this task, participants pressed a button on their keyboard every time they believed one natural and meaningful unit of activity ended and another began. Participants segmented each video twice, once to identify the largest (coarse) units and once to identify the smallest (fine) units. Due to a programming issue, most participants segmented at a coarse grain before they segmented at the fine grain (120 vs 32). Segmentation rates for the participants who performed the fine segmentation task first showed the same qualitative pattern as the full sample (Figure S2), though no formal analyses were performed due to the small sample size. At the beginning of the task participants segmented a practice video (99 seconds long) during which a person sat outside, ate snacks, looked through books, and used his phone. The practice was repeated if the participant did not press the button within an expected range (coarse: 2-6 times, or 1.212-3.636 per minute; fine: 12-30 times, or 7.273-18.182 per minute). The practice was performed at the beginning of the task and during the middle of the task, when the segmentation grain was changed. Videos were ordered such that setting alternated most frequently, activity alternated intermediately, and segmentation grain alternated least frequently. After collapsing across activities, the task design resulted in a three-factor design with one betweensubjects factor, cultural background (Indian Viewer/Us Viewer), and two within-subjects factors, segmentation grain (coarse/fine) and setting (Indian Setting/US Setting).

Questionnaires and Demographics. Once the participant segmented each video twice, they were shown a still frame from each video and asked to rate (1) how familiar he or she as with the activity depicted in the video, and (2) whether the activity in the video was similar to how he or she performs the activity. Each rating was made on a scale from one to seven, with 1 indicating low familiarity or similarity and 7 indicating high familiarity or similarity. Participants' ratings of similarity and familiarity were influenced by their culture, the setting in which the activity was recorded, and the activity itself.

Participants completed three surveys on Qualtrics. First, they completed the Analysis-Holism scale (4) to measure their tendency towards adopting an analytic or holistic processing style. This survey asks participants to indicate how much they agree or disagree with 24 statements using a 7-point scale. After a subset of these ratings were reverse coded, all ratings were summed to create a composite analysis-holism score (A-H score) for each individual. Next, participants completed the Self-Construal Scale (5). Again, participants indicate how much they agree or disagree with 30 statements using a 7point scale. Scores from 15 of these were summed to create the independence score. The remaining 15 were summed to create an interdependence score. Previous research suggests that these scores measure different aspects of how one construes their relationship to others (5).

Finally, participants provided demographic data: age, gender, race and ethnicity, country of residence, country primarily residing in over the past 10 years, country of origin, whether the participant has travelled to India or the United States (and duration of stay), primary language, secondary languages, and number of years of education for themselves and their parents. These data are reported in Tables S4 and S5. 


\section{Results}

\section{Independence and Interdependence}

The data (Table S6) suggest that the Indian viewers rated the self as being more interdependent with others than did the US viewers. They also had greater scores for analysis-holism when reverse coded items were included and when they were excluded.

\section{Familiarity Manipulation Check}

Participants rated activities as more familiar and more similar when the activity was recorded in the setting that matched their culture than when it was recorded in the other setting (e.g., Indian viewers rated activities set in India as more familiar than those set in the US). Though this congruency effect was present for all activities, an examination of Table S3 suggests it was larger for the coffee activity and smallest for the dishes activity. This pattern was supported by the results of linear mixed effects models fit to familiarity and similarity ratings using lme4 and lmerTest in R. These models included setting (India/US), viewer culture (Indian viewer/US viewer), and activity (bed/coffee/dishes/laundry) as fixed effects and a random intercept for subject. Both similarity and familiarity ratings were influenced by the interaction of the viewer culture, the activity setting, and the activity: familiarity culture $\mathrm{x}$ setting $\mathrm{x}$ activity interaction, $\mathrm{F}(3,442.17)=7.137, \mathrm{p}=.0001$; similarity culture $\mathrm{x}$ setting $\mathrm{x}$ activity interaction, $\mathrm{F}(3$, $443.51)=5.900, \mathrm{p}=.0006$.

This study was designed for averaging over activities in order to keep the study duration to under an hour and a half, while allowing or a wider range of activities to be included in the study. By doing this, we were able to manipulate activity setting and grain within subjects and vary activity between participants. However, because the effects of viewer culture and activity setting on familiarity and similarity were greater for some activities than others, it was possible that an effect of familiarity on segmentation might have been present for some activities, but not others. Because familiarity makes the strongest predictions about segmentation rate and alignment, we visualized the segmentation rate and hierarchical alignment data for each activity. In addition, because the coffee activity showed the greatest interaction between viewer culture and setting in both familiarity and similarity, we analyzed the data for the coffee activity on its own.

For segmentation rate, an ANOVA with activity setting, grain, and viewer culture as factors was performed on only the coffee activity segmentation data. The data were consistent with the analyses that collapsed across activities: US viewers identified more fine events in the coffee activity than Indian viewers for both activity settings, main effect of grain, $\mathrm{F}(1,76)=118.969, \mathrm{p}<.001, \mathrm{n}_{\mathrm{p}}{ }^{2}=.610$, main effect of viewer culture, $\mathrm{F}(1,76)=4.004, \mathrm{p}=.049, \mathrm{n}_{\mathrm{p}}{ }^{2}=.050$, culture $\mathrm{x}$ grain interaction, $\mathrm{F}(1,76)=$ $5.697, \mathrm{p}=.020, \mathrm{n}_{\mathrm{p}}^{2}=.070$, all others, largest $\mathrm{F}(1,76)=2.285, \mathrm{p}=.135$.

For enclosure (Figure S4), an ANOVA with activity setting and viewer culture as factors was performed on the data from the coffee activity only. Neither main effect or the interaction reached significance, largest $F(1,76)=1.507, p=.223$. For alignment (Figure S5), the ANOVA included activity setting, viewer culture, and score type (expected/observed). Observed distances were smaller than expected differences, mean effect of score type $\mathrm{F}(1,76)=75.575, \mathrm{p}<.001, \mathrm{n}_{\mathrm{p}}{ }^{2}=.499$, and this difference was greater for the US setting, setting $x$ score type interaction $F(1,76)=5.497, \mathrm{p}=.022, \mathrm{n}_{\mathrm{p}}^{2}=.067$. However, this effect did not significantly interact with viewer culture, viewer culture $\mathrm{x}$ setting $\mathrm{x}$ score type interaction $\mathrm{F}(1,76)=0.089, \mathrm{p}=.7661$. These results are consistent with those performed after averaging across activities. 


\section{Hierarchical Organization Analysis}

If viewers nest fine events within coarse events, then coarse boundaries should be closer to fine boundaries than expected by chance --alignment (6). If coarse events contain fine events, then coarse boundaries also should tend to follow, rather than precede, nearby fine boundaries -- enclosure (7). By both metrics, Indian and US viewers demonstrated hierarchical segmentation: observed vs. expected alignment for Indian viewers, $t(73)=-3.848, p=.0003, d=-0.457$, and for US viewers, $t(77)=-2.614, p$ $=.011, d=-0.401$; enclosure for Indian viewers, $t(73)=7.15, p<.0001, d=0.831$, and US viewers, $t(77)$ $=5.0, p<.0001, d=0.574$ (Table S9-S11). In addition, there was no evidence that alignment or enclosure was influenced by the interaction of viewer culture and activity setting, for all score type $\mathrm{x}$ setting interactions on alignment, largest $F(1,150)=1.015, p=.315$, for the main effect and interaction of setting on enclosure, largest $F(1,150)=1.762, p=.186$.

\section{Agreement Analyses with Matched Button Press Rates}

We evaluated whether differences in agreement across groups reflected differences in segmentation rate. For each US viewer, activity, and grain, segmentation performance was paired with that of an Indian viewer in the same condition, whose segmentation rate most closely matched, but fell below that of the US viewer. Boundaries identified by the US viewer were then randomly dropped until the number matched that of the paired Indian viewer. The analysis was then conducted as before by determining the group time series and calculating the agreement index for each individual, group, grain, and video. Data were then collapsed across videos within activity setting, and a repeated measures ANOVA with viewer culture, group culture, activity setting, and grain was then conducted. The results mirrored those reported on the full data set (Tables S18-S21). 
Bed
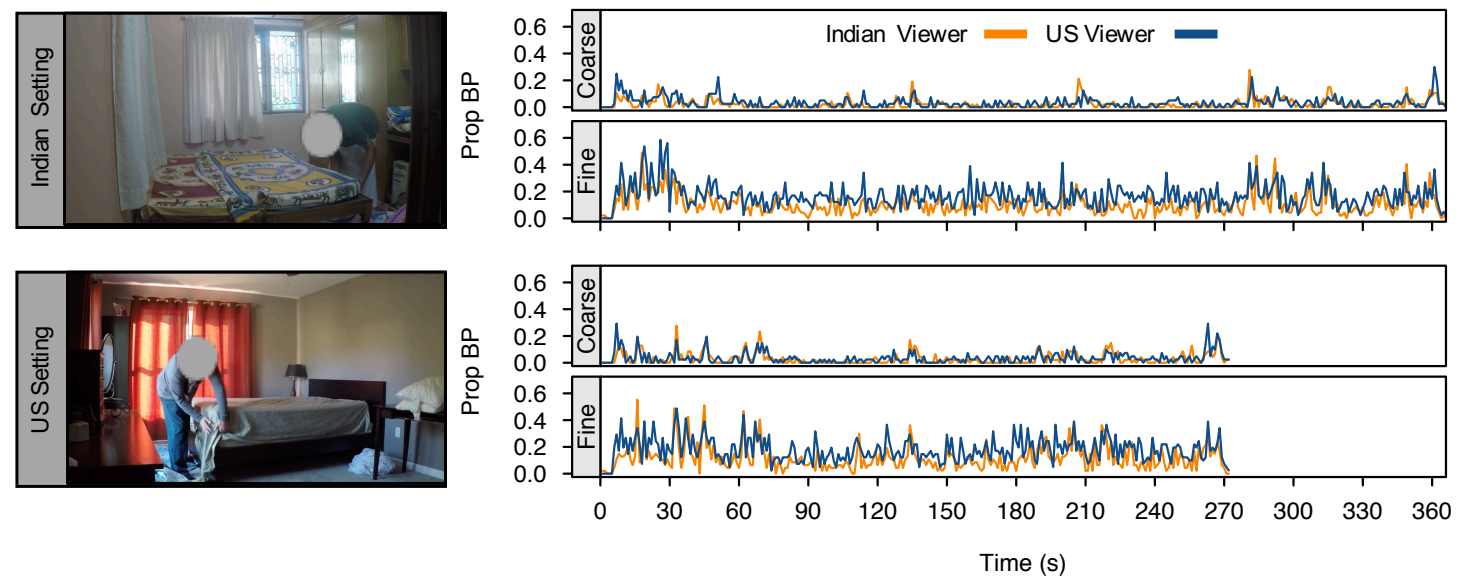

\section{Coffee}
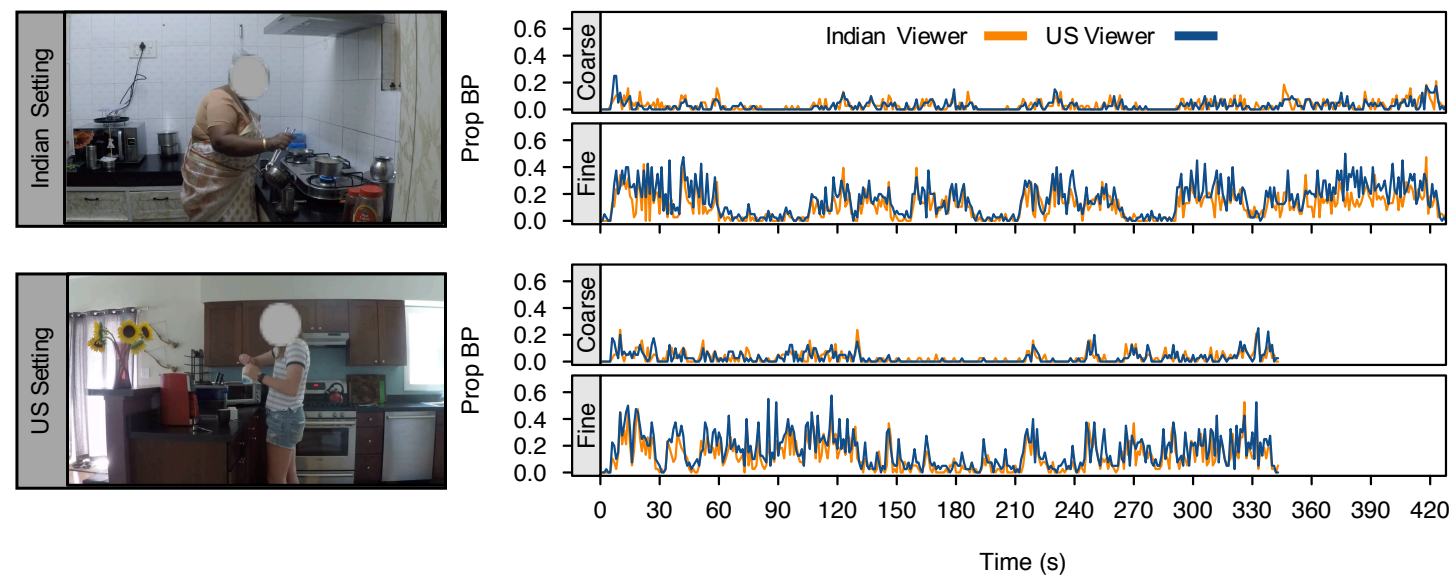

\section{Dishes}
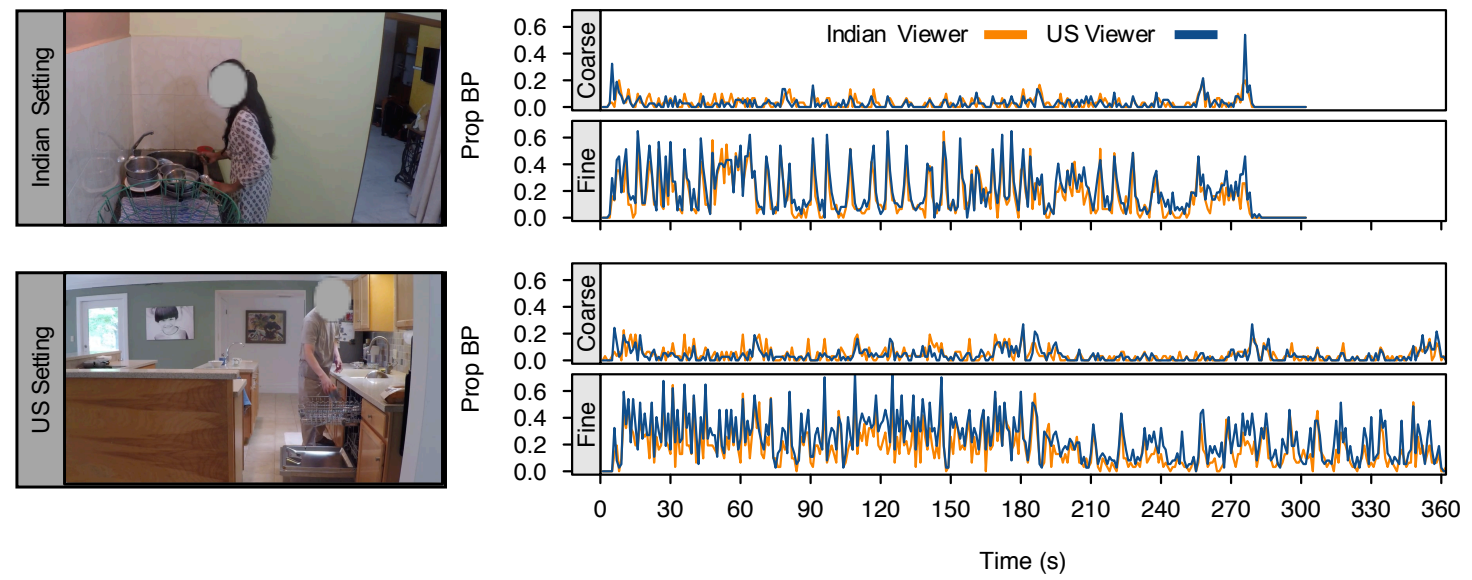

Fig. S1. Frames and group time series for the bed, coffee, and dishes activities (see main text for laundry activities). 
CULTURE AND EVENT SEGMENTATION 35 


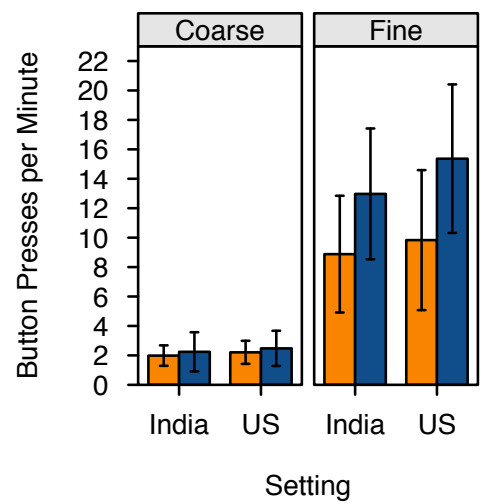

Fig. S2. Segmentation rates for participants that performed the fine segmentation task first $(\mathrm{N}=32)$. Error bars indicate $95 \%$ confidence intervals around the mean. 


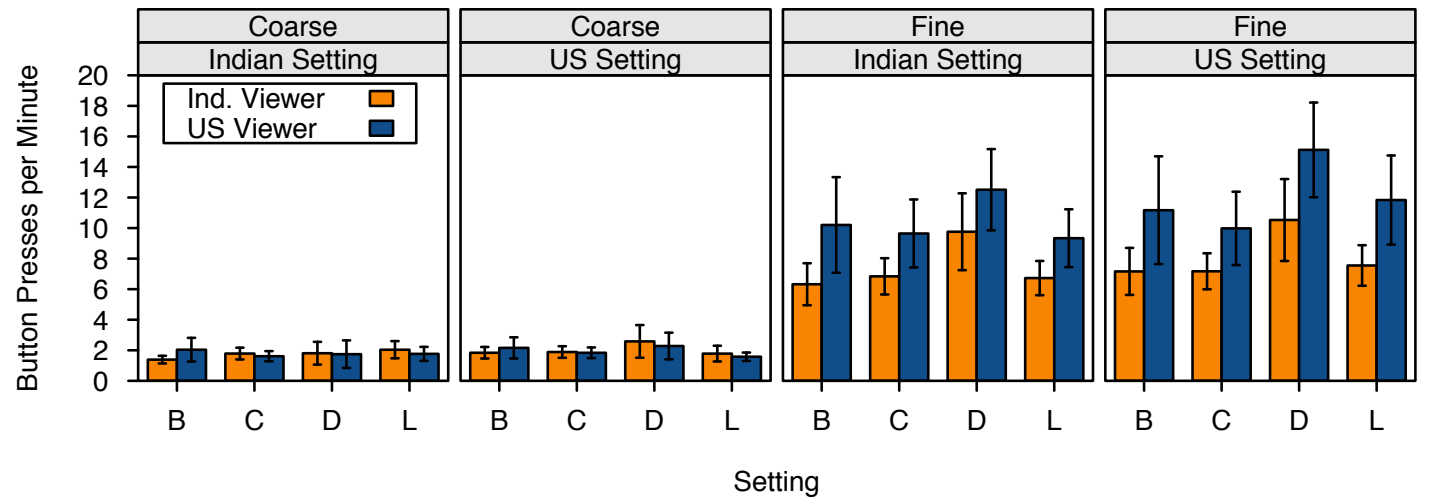

Fig. S3. Segmentation rates across activities, settings, segmentation grains, and viewer cultures. US viewers identified more fine boundaries than Indian viewers for every activity and in each setting. For activity $\mathrm{B}=$ making the bed; $\mathrm{C}=$ making coffee; $\mathrm{D}=$ doing the dishes; $\mathrm{L}=$ doing laundry. Error bars indicate $95 \%$ confidence intervals. 


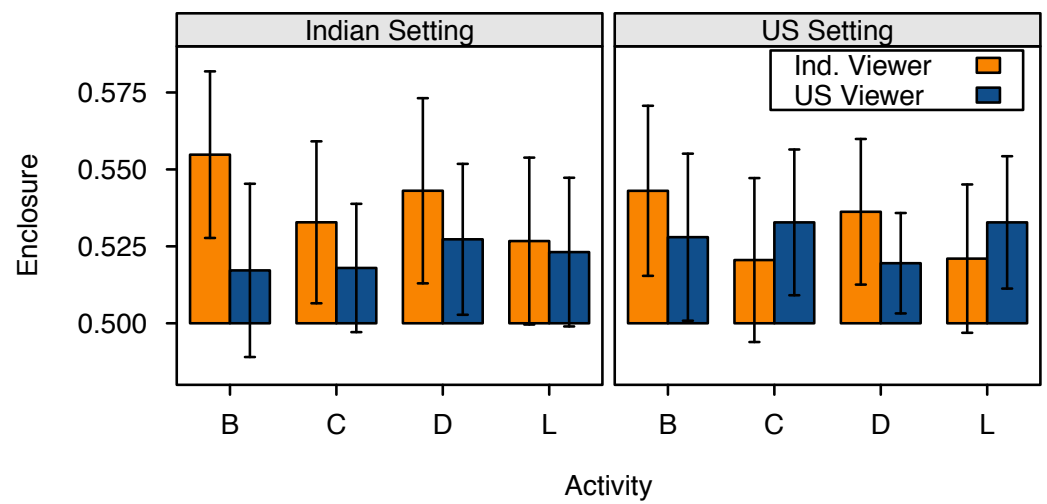

Fig. S4. Enclosure scores (the probability that a coarse boundary came after the nearest fine boundary) across activities, settings, and viewer cultures. For activity $\mathrm{B}=$ making the bed; $\mathrm{C}=$ making coffee; $\mathrm{D}=$ doing the dishes; $\mathrm{L}=$ doing laundry. Error bars indicate $95 \%$ confidence intervals. 


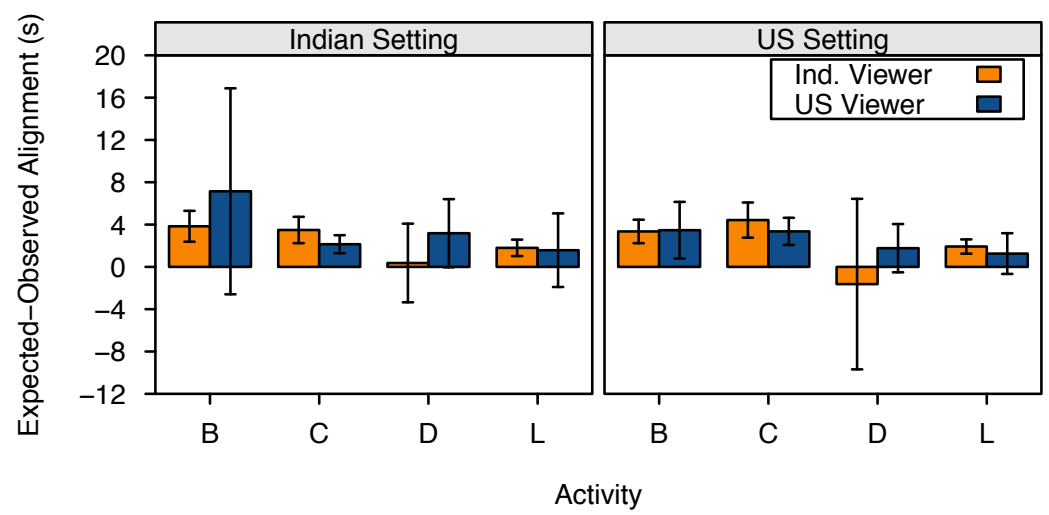

Fig. S5. Alignment of coarse boundaries with fine boundaries across activities, settings, segmentation grains, and viewer cultures. Alignment is indexed by the difference between the average expected and observed distance between a coarse boundary and its nearest fine boundary. Higher values indicate the observed alignment was better than that expected by chance. Examination of alignment for the coffee activity suggests that familiarity had little effect on this measure (Indian viewers showed numerically greater alignment than US viewers for the activity in both settings). For activity $\mathrm{B}=$ making the bed; $\mathrm{C}=$ making coffee; $\mathrm{D}=$ doing the dishes; $\mathrm{L}=$ doing laundry. Error bars indicate $95 \%$ confidence intervals. 
Table S1. Duration of each video in seconds.

\begin{tabular}{lcccc}
\hline & Bed & Coffee & Dishes & Laundry \\
\hline Indian Setting & 363 & 428 & 282 & 280 \\
US Setting & 273 & 344 & 362 & 325 \\
\hline
\end{tabular}


Table S2. Number of participants that segmented each activity.

\begin{tabular}{lccccc}
\hline & Bed & Coffee & Dishes & Laundry & Total $\left(\mathrm{N}^{* 2}\right)$ \\
\hline Indian Viewers & 47 & 38 & 31 & 32 & 148 \\
US Viewers & 41 & 40 & 37 & 38 & 156 \\
\hline
\end{tabular}


CULTURE AND EVENT SEGMENTATION 42

Table S3. Self-reported race and ethnicity of participants.

\begin{tabular}{|c|c|c|c|c|c|c|c|c|c|c|}
\hline & Race & & & & & & & Ethnicity & & \\
\hline & $\begin{array}{l}\text { African } \\
\text { American }\end{array}$ & $\begin{array}{l}\text { American } \\
\text { Indian }\end{array}$ & $\begin{array}{l}\text { East } \\
\text { Asian }\end{array}$ & $\begin{array}{l}\text { Latin } \\
\text { American }\end{array}$ & Multiple & $\begin{array}{l}\text { South } \\
\text { Asian }\end{array}$ & White & Hispanic & $\begin{array}{l}\text { Not } \\
\text { Hispanic } \\
\text { or } \\
\text { Latino }\end{array}$ & $\begin{array}{l}\text { Not } \\
\text { Reported }\end{array}$ \\
\hline $\begin{array}{l}\text { Indian } \\
\text { Viewers }\end{array}$ & 1 & 3 & 3 & & 1 & 66 & & 1 & 70 & 3 \\
\hline $\begin{array}{l}\text { US } \\
\text { Viewers }\end{array}$ & 8 & & 6 & 2 & 5 & 2 & 55 & 7 & 71 & \\
\hline
\end{tabular}


Table S4. Self-reported first languages of participants.

\begin{tabular}{lllll} 
& English & Hindi & Tamil & Other \\
\hline Indian Viewers & 26 & 19 & 20 & 9 \\
US Viewers & 76 & & & 2 \\
\hline
\end{tabular}


Table S5. Mean and standard deviation (in parentheses) of participant's educational background.

Years of Education

\begin{tabular}{lccc} 
& Self & Mother & Father \\
\hline Indian Viewers & $17.72(2.47)$ & $11.8(3.88)$ & $13.59(3.97)$ \\
US Viewers & $15.37(2.37)$ & $13.78(2.73)$ & $13.79(3.22)$ \\
\hline
\end{tabular}


Table S6. Group scores on self-construal and analysis-holism scales, including, mean, standard deviation (in parentheses), Cronbach's $\alpha$, and paired t-tests of the group means.

\begin{tabular}{lccccccccc}
\hline & \multicolumn{2}{c}{ India } & & US & & \multicolumn{4}{c}{ Welch Two Sample $t$-test } \\
& Mean (SD) & $\alpha$ & Mean (SD) & $\alpha$ & $t$ & $d f$ & $p$ & $d$ \\
\hline Independence & $76.04(10.85)$ & 0.81 & $73.83(11.9)$ & 0.8 & 1.196 & 149.77 & 0.234 & 0.194 \\
Interdependence & $78.99(11.97)$ & 0.89 & $65.94(14.59)$ & 0.89 & 6.043 & 146.99 & $<.001$ & 0.976 \\
Analysis-Holism-All & $120.77(15.62)$ & 0.78 & $108.36(14.67)$ & 0.79 & 5.043 & 148.04 & $<.001$ & 0.820 \\
Analysis-Holism-Exc & $95.23(12.96)$ & 0.85 & $86.97(13.47)$ & 0.85 & 3.852 & 149.97 & $<.001$ & 0.624 \\
\hline Note: Reverse coded items were included in Analysis-Holism-All and excluded from Analysis-Holism-
\end{tabular}
Exc. 
Table S7. Mean and standard deviation (in parentheses) of familiarity and similarity ratings for each activity

\begin{tabular}{lcccccccc}
\hline & \multicolumn{2}{c}{ Bed } & \multicolumn{2}{c}{ Coffee } & \multicolumn{2}{c}{ Dishes } & \multicolumn{2}{c}{ Laundry } \\
& India & US & India & US & India & US & India & US \\
\hline Familiarity & & & & & & & & \\
Indian & 6.38 & 5.45 & 5.87 & 4.48 & 6.33 & 5.23 & 6.24 & 5.06 \\
Viewers & $(0.84)$ & $(1.47)$ & $(1.45)$ & $(1.73)$ & $(1.09)$ & $(1.65)$ & $(1.39)$ & $(1.68)$ \\
US & 5.03 & 6.23 & 3.45 & 6.06 & 6.26 & 6.6 & 5.08 & 6.27 \\
Viewers & $(1.76)$ & $(1.33)$ & $(1.91)$ & $(1.46)$ & $(1.04)$ & $(1.14)$ & $(1.88)$ & $(1.37)$ \\
Similarity & & & & & & & & \\
Indian & 5.83 & 4.95 & 5.19 & 3.03 & 6.37 & 4.1 & 5.52 & 4.3 \\
Viewers & $(1.15)$ & $(1.47)$ & $(1.85)$ & $(1.74)$ & $(1.03)$ & $(1.63)$ & $(1.35)$ & $(1.98)$ \\
US & 3.71 & 5.8 & 2.48 & 5.42 & 4.86 & 4.8 & 3.49 & 5.65 \\
Viewers & $(1.74)$ & $(1.11)$ & $(1.91)$ & $(1.6)$ & $(1.61)$ & $(2.11)$ & $(1.64)$ & $(1.49)$ \\
\hline
\end{tabular}


Table S8. ANOVA table for button presses per minute analysis.

\begin{tabular}{lllllll}
\hline Effect & SSEffect & SSResid & $F$ & $d f$ & $p$ & $n_{p}{ }^{2}$ \\
\hline Grain & 8724 & 5328 & 245.58 & 1,150 & $<.001$ & .621 \\
Viewer Culture & 490 & 8126 & 9.043 & 1,150 & 0.003 & .057 \\
Activity Setting & 70.99 & 175.36 & 60.72 & 1,150 & $<.001$ & .288 \\
Grain x Culture & 480 & 5328 & 13.51 & 1,150 & $<.001$ & .083 \\
Grain x Setting & 31.41 & 153.76 & 30.647 & 1,150 & $<.001$ & .170 \\
Culture x Setting & 5.76 & 175.36 & 4.93 & 1,150 & 0.028 & .032 \\
Grain x Culture x Setting & 9.12 & 153.76 & 8.894 & 1,150 & 0.003 & .056 \\
\hline
\end{tabular}


Table S9. Mean and standard deviations of alignment and enclosure scores across viewer culture and activity setting.

\begin{tabular}{lcccccc}
\hline \multicolumn{4}{c}{ Enclosure } & \multicolumn{4}{c}{ Alignment } \\
& $\begin{array}{l}\text { Indian } \\
\text { Setting }\end{array}$ & US & Setting & & & \\
& & & & & \\
& Observed & Observed & Expected & Observed & Expected & Observed \\
\hline Indian & 0.62 & 0.593 & 6.234 & 3.637 & 5.768 & 3.412 \\
Viewer & $(0.191)$ & $(0.167)$ & $(5.142)$ & $(5.423)$ & $(4.002)$ & $(7.479)$ \\
US & 0.563 & 0.585 & 6.391 & 2.862 & 4.757 & 2.259 \\
Viewer & $(0.167)$ & $(0.162)$ & $(14.87)$ & $(3.655)$ & $(6.155)$ & $(2.556)$ \\
\hline
\end{tabular}

Note: Expected values for enclosure are .5. Expected values for alignment are the average distance between a coarse boundary and its nearest fine boundary if it is randomly placed. 
CULTURE AND EVENT SEGMENTATION 49

Table S10. ANOVA table for alignment analysis.

\begin{tabular}{lllllll}
\hline Effect & SSEffect & SSResid & $F$ & $d f$ & $p$ & $n_{p}{ }^{2}$ \\
\hline Score Type & 1151 & 10216 & 16.905 & 1,150 & $<.001$ & 0.101 \\
Viewer Culture & 74 & 15733 & 0.701 & 1,150 & 0.404 & 0.005 \\
Activity Setting & 83.7 & 2509.7 & 5.003 & 1,150 & 0.027 & 0.032 \\
Score Type x Culture & 11 & 10216 & 0.161 & 1,150 & 0.689 & 0.001 \\
Score Type x Setting & 15.9 & 2345.4 & 1.015 & 1,150 & 0.315 & 0.007 \\
Culture x Setting & 22.7 & 2509.7 & 1.359 & 1,150 & 0.246 & 0.009 \\
Score Type x Culture x Setting & 5.9 & 2345.4 & 0.379 & 1,150 & 0.539 & 0.003 \\
\hline
\end{tabular}


Table S11. ANOVA table for enclosure analysis.

\begin{tabular}{lllllll}
\hline Effect & SSEffect & SSResid & $F$ & $d f$ & $p$ & $n_{p}{ }^{2}$ \\
\hline Viewer Culture & 0.08 & 4.951 & 2.413 & 1,150 & 0.122 & 0.016 \\
Video Setting & 0 & 3.925 & 0.011 & 1,150 & 0.918 & 0.000 \\
Culture x Setting & 0.046 & 3.925 & 1.762 & 1,150 & 0.186 & 0.012 \\
\hline
\end{tabular}


Table S12. ANOVA table for agreement analysis.

\begin{tabular}{lllllll}
\hline Effect & SSEffect & SSResid & $F$ & $d f$ & $p$ & $n_{p}{ }^{2}$ \\
\hline Grain & 13.819 & 2.508 & 826.44 & 1,150 & $<.001$ & .846 \\
Viewer Culture & 0.374 & 9.517 & 5.89 & 1,150 & .016 & .038 \\
Activity Setting & 0.1799 & 1.2873 & 20.963 & 1,150 & $<.001$ & .123 \\
Group Culture & 0.0425 & 0.9875 & 6.45 & 1,150 & .012 & .041 \\
Grain x Culture & 0.109 & 2.508 & 6.52 & 1,150 & .012 & .042 \\
Grain x Setting & 0.008 & 1.1355 & 1.053 & 1,150 & .306 & .007 \\
Grain x Group Culture & 0.0047 & 0.511 & 1.373 & 1,150 & .243 & .009 \\
Culture x Setting & 0.0171 & 1.2873 & 1.994 & 1,150 & .16 & .013 \\
Culture x Group Culture & 0.093 & 0.9875 & 14.13 & 1,150 & $<.001$ & .086 \\
Setting x Group Culture & 0.0069 & 0.3605 & 2.865 & 1,150 & .093 & .019 \\
Grain x Culture x Setting & 0.0035 & 1.1355 & 0.459 & 1,150 & .499 & .003 \\
Grain x Culture x Group Culture & 0.0883 & 0.511 & 25.917 & 1,150 & $<.001$ & .147 \\
Grain x Setting x Group Culture & 0.0015 & 0.3519 & 0.642 & 1,150 & .424 & .004 \\
Culture x Setting x Group Culture & 0 & 0.3605 & 0 & 1,150 & .983 & 0 \\
Grain x Culture x Setting x Group Culture & 0.003 & 0.3519 & 1.266 & 1,150 & .262 & 0.008 \\
\hline
\end{tabular}


CULTURE AND EVENT SEGMENTATION 52

Table S13. ANOVA table for agreement analysis (coarse only).

\begin{tabular}{lllllll}
\hline Effect & SSEffect & SSResid & $F$ & $d f$ & $p$ & $n_{p}{ }^{2}$ \\
\hline Viewer Culture & 0.443 & 5.714 & 11.63 & 1,150 & 0.001 & 0.072 \\
Activity Setting & 0.1318 & 1.7376 & 11.378 & 1,150 & 0.001 & 0.071 \\
Group Culture & 0.0377 & 1.1913 & 4.742 & 1,150 & 0.031 & 0.031 \\
Culture x Setting & 0.018 & 1.7376 & 1.554 & 1,150 & 0.214 & 0.010 \\
Culture x Group Culture & 0 & 1.1913 & 0.004 & 1,150 & 0.951 & 0 \\
Setting x Group Culture & 0.0074 & 0.6293 & 1.767 & 1,150 & 0.186 & 0.012 \\
Culture x Setting x Group Culture & 0.0015 & 0.6293 & 0.368 & 1,150 & 0.545 & 0.002 \\
\hline
\end{tabular}


CULTURE AND EVENT SEGMENTATION 53

Table S14. ANOVA table for agreement analysis (fine only).

\begin{tabular}{lllllll}
\hline Effect & SSEffect & SSResid & $F$ & $d f$ & $p$ & $n_{p}{ }^{2}$ \\
\hline Viewer Culture & 0.04 & 6.311 & 0.939 & 1,150 & 0.334 & 0.006 \\
Activity Setting & 0.0561 & 0.6851 & 12.275 & 1,150 & 0.001 & 0.076 \\
Group Culture & 0.00948 & 0.30723 & 4.627 & 1,150 & 0.033 & 0.030 \\
Culture x Setting & 0.0026 & 0.6851 & 0.566 & 1,150 & 0.453 & 0.004 \\
Culture x Group Culture & 0.18128 & 0.30723 & 88.506 & 1,150 & $<.001$ & 0.371 \\
Setting x Group Culture & 0.00098 & 0.08299 & 1.764 & 1,150 & 0.186 & 0.012 \\
Culture x Setting x Group Culture & 0.00143 & 0.08299 & 2.578 & 1,150 & 0.110 & 0.017 \\
\hline
\end{tabular}


CULTURE AND EVENT SEGMENTATION 54

Table S15. Estimated effects of visual activity and change type on the likelihood that viewers identified a coarse or fine boundary.

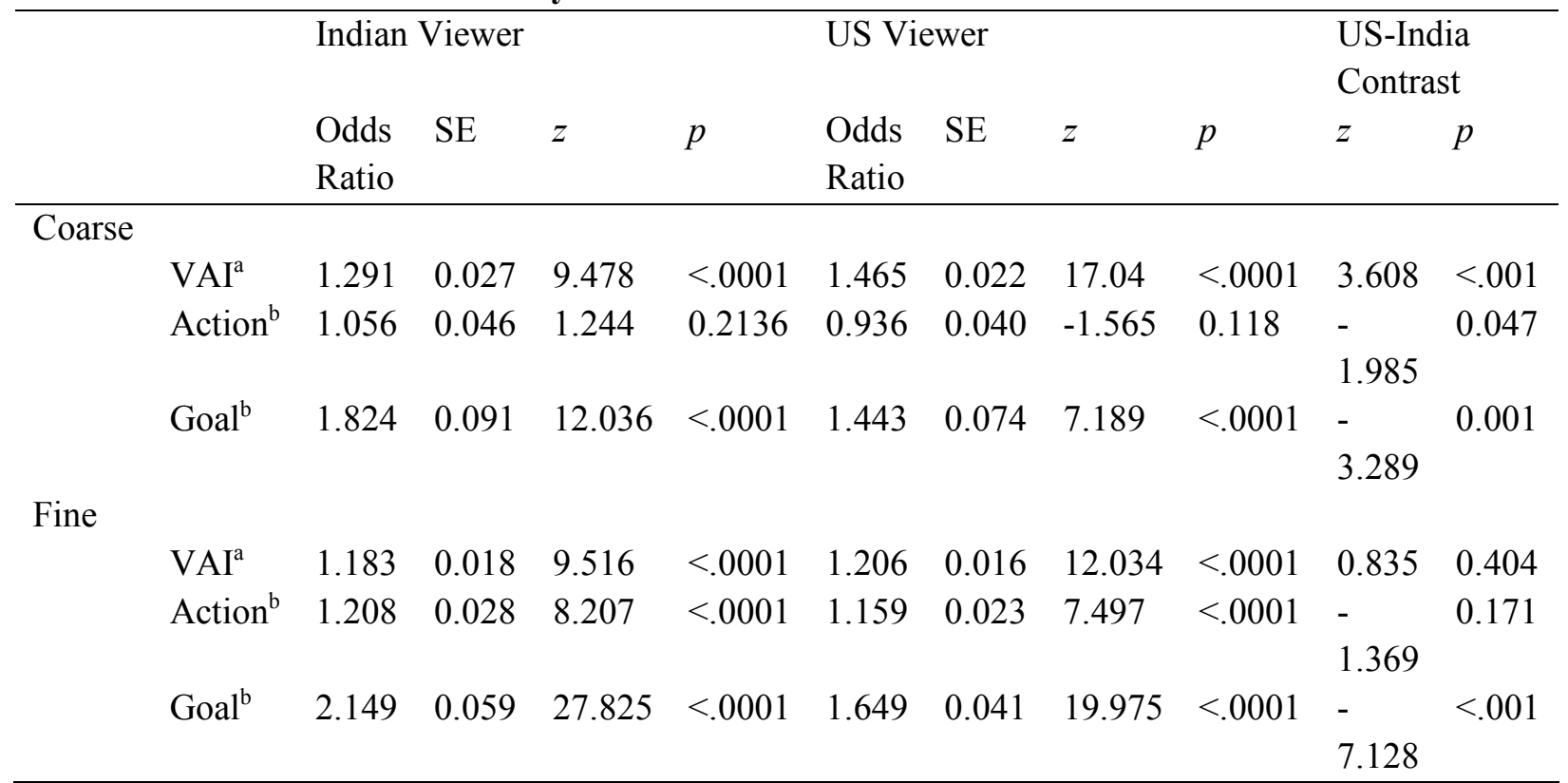

a. Odds ratio reflects the increase in the odds of identifying a boundary when VAI increased by 1 standard deviation.

b. Odds ratio reflects the increase in the odds of identifying a boundary when an action or goal change was present, relative to when no change was present. 
CULTURE AND EVENT SEGMENTATION 55

Table S16. Estimated effects of visual activity and change type on the likelihood that a coarse or fine boundary was identified for activities in each setting.

\begin{tabular}{|c|c|c|c|c|c|c|c|c|c|c|c|}
\hline & & \multicolumn{2}{|c|}{ Indian Setting } & \multirow[b]{2}{*}{$\mathrm{z}$} & \multirow[b]{2}{*}{$\mathrm{p}$} & \multicolumn{2}{|c|}{ US Setting } & \multirow[b]{2}{*}{$\mathrm{z}$} & \multirow[b]{2}{*}{$\mathrm{p}$} & \multicolumn{2}{|c|}{$\begin{array}{l}\text { US-India } \\
\text { Contrast }\end{array}$} \\
\hline & & $\begin{array}{l}\text { Odds } \\
\text { Ratio }\end{array}$ & SE & & & $\begin{array}{l}\text { Odds } \\
\text { Ratio }\end{array}$ & SE & & & $\mathrm{z}$ & $\mathrm{p}$ \\
\hline \multicolumn{12}{|l|}{ Coarse } \\
\hline & $\mathrm{VAI}^{\mathrm{a}}$ & 1.396 & 0.026 & 12.702 & $<.001$ & 1.355 & 0.023 & 13.080 & $<.001$ & -0.860 & 0.390 \\
\hline & Action $^{\mathrm{b}}$ & 1.063 & 0.046 & 1.403 & 0.161 & 0.930 & 0.040 & -1.701 & 0.089 & -2.193 & 0.028 \\
\hline & Goal $^{\mathrm{b}}$ & 1.595 & 0.085 & 8.755 & $<.001$ & 1.650 & 0.078 & 10.550 & $<.001$ & 0.478 & 0.632 \\
\hline \multicolumn{12}{|l|}{ Fine } \\
\hline & $\mathrm{VAI}^{\mathrm{a}}$ & 1.174 & 0.017 & 9.310 & $<.001$ & 1.215 & 0.016 & 12.158 & $<.001$ & 1.475 & 0.140 \\
\hline & Action $^{\mathrm{b}}$ & 1.248 & 0.027 & 10.203 & $<.001$ & 1.121 & 0.024 & 5.431 & $<.001$ & -3.539 & $<.001$ \\
\hline & Goal $^{\mathrm{b}}$ & 2.301 & 0.061 & 31.472 & $<.001$ & 1.540 & 0.040 & 16.539 & $<.001$ & $\begin{array}{l}- \\
10.797\end{array}$ & $<.001$ \\
\hline
\end{tabular}

a. Odds ratio reflects the increase in the odds of identifying a boundary when VAI increased by 1 standard deviation.

b. Odds ratio reflects the increase in the odds of identifying a boundary when an action or goal change was present, relative to when no change was present. 
Table S17. Tests of generalized linear mixed effects models describing the effects of the VAI and action and goal changes on coarse segmentation.

\begin{tabular}{lllll}
\hline Effect & SSEffect & $F$ & $d f$ & $p$ \\
\hline VAI & 368.08 & 330.442 & 1 & $<.0001$ \\
Change Type & 206.97 & 100.512 & 2 & $<.0001$ \\
Viewer Culture & 0.02 & 0.405 & 1 & 0.5248 \\
Activity Setting & 2.42 & 2.508 & 1 & 0.1133 \\
VAI x Culture & 11.88 & 13.02 & 1 & 0.0003 \\
VAI x Setting & 11.09 & 0.739 & 1 & 0.3899 \\
Change Type x Culture & 1.22 & 6.021 & 2 & 0.0024 \\
Change Type x Setting & 5.78 & 3.054 & 2 & 0.0472 \\
Culture x Setting & 0 & 0.29 & 1 & 0.5901 \\
VAI x Culture x Setting & 0.41 & 0.459 & 1 & 0.4979 \\
Change Type x Culture x Setting & 2.09 & 1.066 & 2 & 0.3443
\end{tabular}

Note: F tests and p-values were obtained using joint_tests in the emmeans package, and SSEffect was obtained using lme4's anova. Residual degrees of freedom were 203,370. Effects that included interaction terms between the VAI and Change Type were not included in the model. 
Table S18. Tests of generalized linear mixed effects models describing the effects of the VAI and action and goal changes on fine segmentation.

\begin{tabular}{lllll}
\hline Effect & SSEffect & $F$ & $d f$ & $p$ \\
\hline VAI & 268 & 227.972 & 1 & $<.0001$ \\
Change Type & 1113.96 & 579.527 & 2 & $<.0001$ \\
Viewer Culture & 9.01 & 6.979 & 1 & 0.0082 \\
Activity Setting & 0.82 & 0.159 & 1 & 0.6903 \\
VAI x Culture & 0.39 & 0.698 & 1 & 0.4036 \\
VAI x Setting & 52.37 & 2.175 & 1 & 0.1403 \\
Change Type x Culture & 1.39 & 25.657 & 2 & $<.0001$ \\
Change Type x Setting & 119.62 & 58.393 & 2 & $<.0001$ \\
Culture x Setting & 0.88 & 0.503 & 1 & 0.478 \\
VAI x Culture x Setting & 0.02 & 0.011 & 1 & 0.9171 \\
Change Type x Culture x Setting & 2.13 & 1.068 & 2 & 0.3438
\end{tabular}

Note: F tests and p-values were obtained using joint_tests in the emmeans package, and SSEffect was obtained using lme4's anova. Residual degrees of freedom were 203,370. Effects that included interaction terms between the VAI and Change Type were not included in the model. 
CULTURE AND EVENT SEGMENTATION 58

Table S19. ANOVA table for agreement analysis with matched segmentation rates

\begin{tabular}{lllllll}
\hline Effect & SSEffect & SSResid & $F$ & $d f$ & $p$ & $n_{p}{ }^{2}$ \\
\hline Grain & 13.233 & 2.423 & 819.341 & 1,150 & $<.001$ & 0.845 \\
Viewer Culture & 0.217 & 9.625 & 3.386 & 1,150 & 0.068 & 0.022 \\
Activity Setting & 0.178 & 1.279 & 20.935 & 1,150 & $<.001$ & 0.122 \\
Group Culture & 0.046 & 1.025 & 6.657 & 1,150 & 0.011 & 0.043 \\
Grain x Culture & 0.159 & 2.423 & 9.845 & 1,150 & 0.002 & 0.062 \\
Grain x Setting & 0.012 & 1.252 & 1.480 & 1,150 & 0.226 & 0.010 \\
Grain x Group Culture & 0.003 & 0.539 & 0.822 & 1,150 & 0.366 & 0.006 \\
Culture x Setting & 0.015 & 1.279 & 1.728 & 1,150 & 0.191 & 0.011 \\
Culture x Group Culture & 0.032 & 1.025 & 4.739 & 1,150 & 0.031 & 0.031 \\
Setting x Group Culture & 0.002 & 0.379 & 0.669 & 1,150 & 0.415 & 0.004 \\
Grain x Culture x Setting & 0.000 & 1.252 & 0.008 & 1,150 & 0.929 & 0.000 \\
Grain x Culture x Group Culture & 0.107 & 0.539 & 29.778 & 1,150 & $<.001$ & 0.166 \\
Grain x Setting x Group Culture & 0.000 & 0.381 & 0.099 & 1,150 & 0.753 & 0.001 \\
Culture x Setting x Group Culture & 0.001 & 0.379 & 0.306 & 1,150 & 0.581 & 0.002 \\
Grain x Culture x Setting x Group Culture & 0.004 & 0.381 & 1.461 & 1,150 & 0.229 & 0.010 \\
\hline & & & & & & \\
& & & & & &
\end{tabular}


CULTURE AND EVENT SEGMENTATION 59

Table S20. ANOVA table for agreement analysis with matched segmentation rates (coarse only)

\begin{tabular}{lllllll}
\hline Effect & SSEffect & SSResid & $F$ & $d f$ & $p$ & $n_{p}{ }^{2}$ \\
\hline Viewer Culture & 0.374 & 5.712 & 9.822 & 1,150 & 0.002 & 0.061 \\
Activity Setting & 0.142 & 1.790 & 11.931 & 1,150 & 0.001 & 0.074 \\
Group Culture & 0.036 & 1.269 & 4.234 & 1,150 & 0.041 & 0.027 \\
Culture x Setting & 0.008 & 1.790 & 0.703 & 1,150 & 0.403 & 0.005 \\
Culture x Group Culture & 0.011 & 1.269 & 1.279 & 1,150 & 0.260 & 0.008 \\
Setting x Group Culture & 0.002 & 0.672 & 0.362 & 1,150 & 0.548 & 0.002 \\
Culture x Setting x Group Culture & 0.001 & 0.672 & 0.122 & 1,150 & 0.727 & 0.001 \\
\hline
\end{tabular}


CULTURE AND EVENT SEGMENTATION 60

Table S21. ANOVA table for agreement analysis with matched segmentation rates (fine only)

\begin{tabular}{lllllll}
\hline Effect & SSEffect & SSResid & $F$ & $d f$ & $p$ & $n_{p}{ }^{2}$ \\
\hline Viewer Culture & 0.002 & 6.336 & 0.054 & 1,150 & 0.817 & 0.000 \\
Activity Setting & 0.048 & 0.741 & 9.812 & 1,150 & 0.002 & 0.061 \\
Group Culture & 0.013 & 0.295 & 6.418 & 1,150 & 0.012 & 0.041 \\
Culture x Setting & 0.006 & 0.741 & 1.299 & 1,150 & 0.256 & 0.009 \\
Culture x Group Culture & 0.129 & 0.295 & 65.318 & 1,150 & $<.001$ & 0.303 \\
Setting x Group Culture & 0.000 & 0.087 & 0.548 & 1,150 & 0.461 & 0.004 \\
Culture x Setting x Group Culture & 0.004 & 0.087 & 6.779 & 1,150 & 0.010 & 0.043 \\
\hline
\end{tabular}




\section{References}

1. Petit E HandBrake.

2. Schwartz MF, Reed ES, Montgomery M, Palmer C, Mayer NH (1991) The Quantitative Description of Action Disorganisation after Brain Damage: A Case Study. Cognitive Neuropsychology 8(5):381-414.

3. Newtson D (1973) Attribution and the unit of perception of ongoing behavior. Journal of Personality and Social Psychology 28(1):28-38.

4. Choi I, Koo M, Jong An Choi (2007) Individual Differences in Analytic Versus Holistic Thinking. Pers Soc Psychol Bull 33(5):691-705.

5. Singelis TM (1994) The Measurement of Independent and Interdependent Self-Construals. Pers Soc Psychol Bull 20(5):580-591.

6. Zacks JM, Tversky B, Iyer G (2001) Perceiving, remembering, and communicating structure in events. Journal of Experimental Psychology: General 130(1):29-58.

7. Hard BM, Recchia G, Tversky B (2011) The shape of action. Journal of Experimental Psychology: General 140(4):586-604. 